\title{
CONNECTING STAKEHOLDERS THROUGH EDUCATIONAL TECHNOLOGY FOR EFFECTIVE AND DIGITALISED HIGHER EDUCATION ENVIRONMENTS
}

\author{
Christian-Andreas Schumann, Claudia Tittmann, Kevin Reuther, Helge Gerischer, West Saxon \\ University of Zwickau, Germany, Feng Xiao, Oliver Schirmer, Tongji University Shanghai,
}

China

\section{Introduction}

The idea of "Education for All" is already explained in detail in the corresponding UNESCO World Declaration in the form of a "Framework for Action to Meet Basic Learning Needs" in 1990. Interestingly, challenges for global access to education are being worked out that are still relevant today: Universalising access and promoting equity, focusing on leaning acquisition, broadening the means and scope of basic education, enhancing the environment of learning, strengthening partnerships. Since then, many things have been turned to good, much remains to be done. However, today's omnipresent digitization offers completely new opportunities to live up to this vision. Serious changes and disruptive innovations are pushed by digital transformations. (UNESCO, 1990)

Leveraging ICT for Achieving Education 2030 was the focus of further development in education in the UNESCO Qingdao Declaration in 2015. The connection between ICT as part of general digitization and challenges for education is illustrated by the chosen priorities: Access and inclusion, open educational resources and open solutions, quality learning, lifelong learning pathways, online learning innovations, recognition of online learning, accountability and partnership, international cooperation, etc. (UNESCO, 2015).

The consistent continuation of this approach is being pursued in the European Digital Education Action Plan in 2018, which focuses in particular on challenges and opportunities for digital transformation for education. Priorities are: Making better use of digital technology for teaching and learning, developing relevant digital competences and skills for the digital transformation and improving education through better data analysis and foresight, while still referring to educational policy goals such as support for high-quality education, developing Europeans' digital skills and making them more visible, boosting innovation and digital competences in all education institutions, opening up education systems, etc. (European Commission, 2018)

Planning, implementation and control of teaching and learning processes are now linked to a digitized environment. The use of efficient methods, educational materials and modern technical media are expanded by the dimensions of digitization. International connections, 
relations to the future world of work places as well as community and individual social relationships are increasingly being intertwined in a digitized world and interlinked with the classic aspects of didactics, methodology and content. As a result, education systems are becoming increasingly complex and are characterized by a growing degree of networking. The interaction of stakeholders in educational technology has a significant impact on the generation of effective learning environments in the digitalised education. This particular view on a holistic development problem in education leads to new insights and concepts that are constantly being developed and which are currently being used more and more in practice.

\section{Theoretical approach}

Technology and computer-based working and learning worlds are complex systems whose design can only be successful through a holistic approach. Holisticness always means looking at complete systems, implying a systemic approach. A system is a set of ordered elements with properties that are linked by relations. The set of relations between the elements of a system is its structure. An element is a component of a system that cannot be further broken down within this totality. The order and/or the structure of the elements of a system is its organization in the sense of the system theory. A system is a holistic connection of units (elements) whose relationships with each other differ quantitatively (higher number of interactions) and qualitatively (higher productivity of interactions) from their relationships with other entities. This difference in relationships constitutes a system boundary by which the system differentiates itself from its environment (Feess, 2019).

Learning environments in the context of connecting, equivalent educational technologies form special learning systems that can be understood as a connection between a community of learners or teachers and learners, for example, including connections to future workplaces and global partners beyond their system boundaries. If several such systems are brought together in a global cooperation, this results in mega-systems that are already known from information system theories. Learning systems are combined systems with artificial (humanmade), logical, informal, organisational and social impacts. The interplay between learning system and learning environment is based on sociological system theory, in which a connection is established between the terms system, complexity, communication and meaning (Stichweh, 2011).

The sociological impact on learning systems and their learning environments implies the combination of different theories to understand the processes and the effects of technologybased learning. The investigation of the technology-based interaction of stakeholders in digitized learning worlds is based on a multitude of theories, of which the stakeholder theory and connectivism as learning theory are particularly important. The Triple Helix and the Transparent Knowledge Graphs are helpful in describing the knowledge gained from selected theories as models. 


\section{Connecting Stakeholders through Educational Technology for Effective and Digitalised Higher Education Environments \\ Christian-Andreas Schumann et al.}

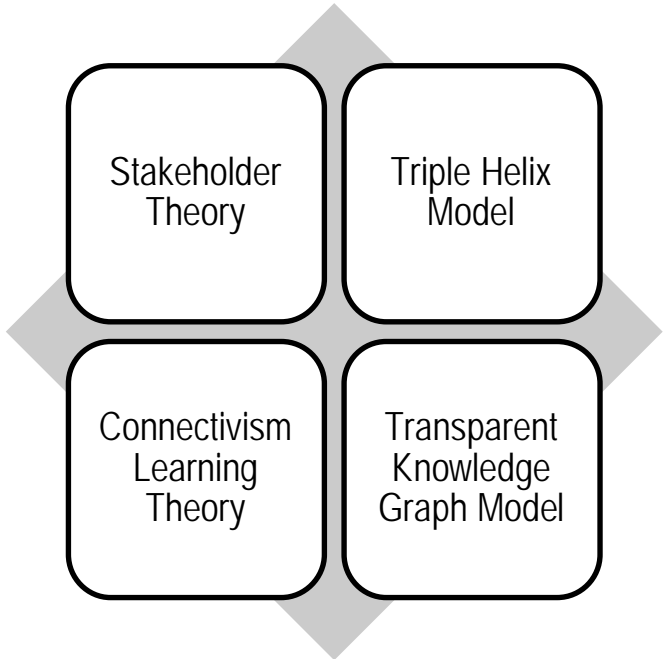

Figure 1. Key theories and models for connecting stakeholders in digital learning environments

Stakeholder theory means that organisations have obligations not only to shareholders but to other interest groups such as customers, employees, providers and the wider community, amongst many others. It is related to system theory, corporate social responsibility, and organisation theory concerning the role of cooperation in social systems and explanation of the behaviour in organisations and their environments. Stakeholders can be defined as any group of people that is affected by or is able to influence the achievement of organisation's objectives (Freeman, 2010).

The Triple Helix concept describes the growing role of the social effects of universities in a hybrid system of university, industrial and governmental processes as well as their interdependencies and interactions in the knowledge society. The aim is to enhance the potential for innovation and business development through new institutional and social formats for the production, transfer and application of knowledge. Thus the model of the interaction of several stakeholders in a new organisational context can be used for case study analysis. In particular, complex institutional processes and relationships and their permanent change can be recognized and influenced in a multi-dimensional social context (Leydesdorff, 2012).

Connectivism describes how an individual brings his networked knowledge to the organizations or institutions that reflect the network knowledge, thereby enabling the individual to continue learning. It brings together elements of chaos, network, complexity and organizational theories. The permanent further learning is more important than the reference to existing knowledge, whereby a suitable mixture between human-centred and technology-based knowledge acquisition is to be found (Siemens, 2005).

Transparent Knowledge Graph Model is based on graph theory, which is used to describe relations between objects using edges and nodes. Knowledge objects are mapped as knowledge nodes and can be used to represent complex, multidimensional relationships in knowledge management. If several links between knowledge objects are grouped together, 
they can be used to describe knowledge paths. The special feature of this model is the increased transparency, which is created by opening the knots and edges by cutting, so that the inner structure and inner processes are revealed. Such knowledge networks based on knowledge graphs can be used to describe networked and technology-driven learning in social environments up to deep learning, thereby building a bridge to connectivism (Tittmann \& Schumann, 2010).

Connecting stakeholders to large networks is a complex challenge in itself, and its complexity is further increased by technology-based digitization in a learning environments. Therefore, more specific theories and concepts based on the system theory are used to derive a conceptual approach.

\section{Conceptual framework}

However, the holistic approach that can be achieved through the application of system theory and related concepts and models should not only be considered technologically and organizationally, but also in terms of behavioural orientation, since the actors in technologybased learning environments enter into cooperations that are influenced by human behavioural patterns combined with technological applications and in the future more and more with artificial intelligence. Behavioural learning theory influences the creation of learning environments (Schunk, 2014; pp.21-25.).

The behaviour is initiated by respective stimuli coming from the environment. It could be strengthened or weakened. In this context, each stakeholder displays a certain behaviour that is characterised by the environment in general and, in concrete terms, by a digitised and technologized learning environment. Therefore, the change in the learning environment caused by the new changes will influence the behaviour positively or negatively. Related to the goal theory, it can still be assumed that the stakeholders pursue goals dependent on the respective environment and shaped not only by cognitive and emotional characteristics, but also by behaviour. (Anderman \& Patrick, 2012)

Following the achievement theory, the motivation of all stakeholders depends on their own condition as well as on the impact of the environment, whereby various dimensions, such as psychological, physical, social, etc., have to be taken into account (Kirikkanat, 2014). This complex structure is positively or negatively influenced by the technologization of learning through additional influences, which is expressed in a further dimension of "digitisation". If the behavioural approaches are now linked to the stakeholder theory, then not only classical relationships to organizations, management and leadership should be in focus, but also the aspects of the positive motivation based on corporate social responsibility and ethical behaviour under the conditions of digitization and technologization.

Stakeholders should be provided with a framework in which motivating conditions for the joint, successful development of educational technologies exist in a digitized learning and cooperation environment. The main issues are skills gaps, low return on investment (ROI), 


\section{Connecting Stakeholders through Educational Technology for Effective and Digitalised Higher Education Environments \\ Christian-Andreas Schumann et al.}

and the need for innovation, entrepreneurship, and job creation. That means strengthening the skills, increasing education's ROI, and enabling all groups to be more innovative. The key aspects for the digital education are integrated digital education ecosystems, integrated learning life cycle, integrated technology solutions, as well as an effective and motivating environment (Banerjee \& Belson, 2015).

All relevant stakeholders must be involved in these processes. The stakeholder groups that are interested, affected or have influence should be identified. The stakeholder analysis is conducted in two phases. First, the stakeholder groups are determined. Second, the role of each stakeholder group is defined (Hanschke, Giesinger, \& Goetze, 2013; p.42).

If the Triple Helix Model is assumed, there are three main roles that remain even under the conditions of technology-based, digital learning worlds: University, Business and Government. Due to the omnipresence of digitisation and the transformations induced by it, each group and each stakeholder must have their own digital literacy capabilities. However, the highly specialised enablers ensuring that each stakeholder group has access to educational technologies and that the group is perceived as competent in the field of digitised learning environments form a subgroup in each group and beyond a cross-group community.

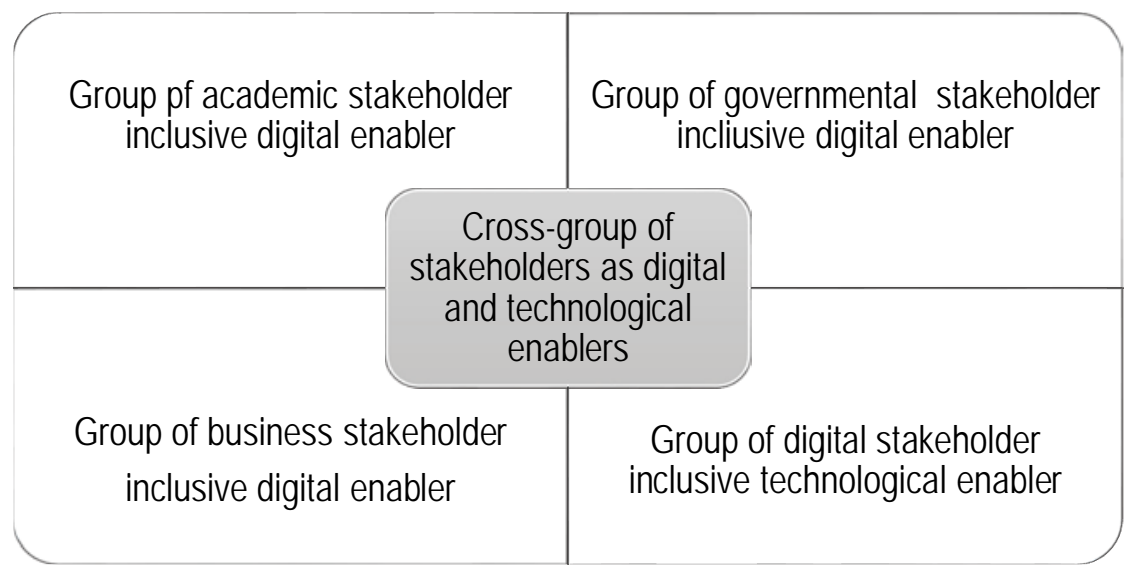

Figure 2. Extended connection of stakeholder groups by digitisation and educational technology

The existing and necessary degree of interdependence and connections between stakeholders and their groups is drastically increased by digitisation in general and educational technologies in particular. Digitised education systems therefore require fundamentally new strategic decisions, in particular the move towards organisationally and digitally networked education systems and the associated stakeholder groups. New educational technologies lead to a dynamization of these processes because they constantly generate new organisational and methodological possibilities and thus imply new behavioural patterns and challenges.

\section{Special connecting model}

The framework for technology-based, digitised education is based on social, ethical and behavioural aspects, as in classical education systems. The new thing is that every view is additionally penetrated by digitalization. Stakeholders and their groups form communities for 
special target groups and application areas, which use the new technological and media possibilities to come together in connected education systems. In order to be able to successfully carry out their diverse and variously interests and motivations as an association or as a network, both individually and in cooperation, they need technology-based and service-oriented connecting subsystems, especially with regard to the new learning environments. These sub-areas are complemented by digital infrastructures and tools for technologized learning and teaching.

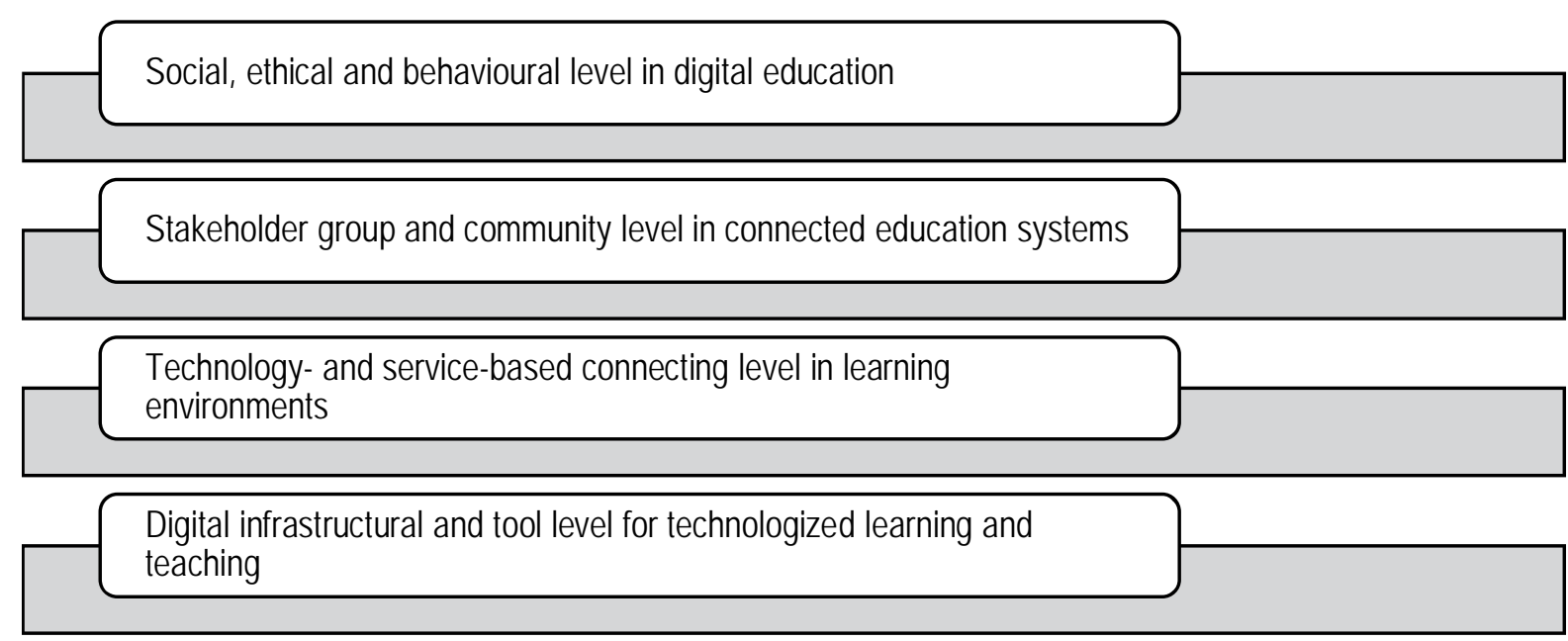

Figure 3. Multilevel connecting model for stakeholders based on educational technology

In organisational-structural terms, this results in a four-level architecture whose individual levels can be specifically designed and modified, but which is all interconnected by cooperative, behaviour-oriented and digital cross-sectional tasks. Connections are the "putty" in such a typical networked system, in which both internal networking at the individual levels and external networking between the levels via connectors and interfaces are established and guarantee the functionality of technology-based learning environments.

\section{Case of application}

Nowadays, stakeholders and their groups work together in networked learning worlds in order to be able to operate national and international successful for joint study offers with several partners. As state of the art, stakeholder networks based on the Triple Helix Model are linked by a service-oriented, technology based architecture to create productive and efficient education systems. Rational education systems based on a process- and function-oriented approach are currently being created. The educational technologies in interaction with the information systems and tools promote the connections by providing services for the control and operation of the educational networks and learning environments as well as for related applications with their help. The connections to the social, ethical and behavioural aspects of digital education should be further developed by means of suitable services in order to further increase the learning effectiveness. 


\section{Connecting Stakeholders through Educational Technology for Effective and Digitalised Higher Education Environments \\ Christian-Andreas Schumann et al.}

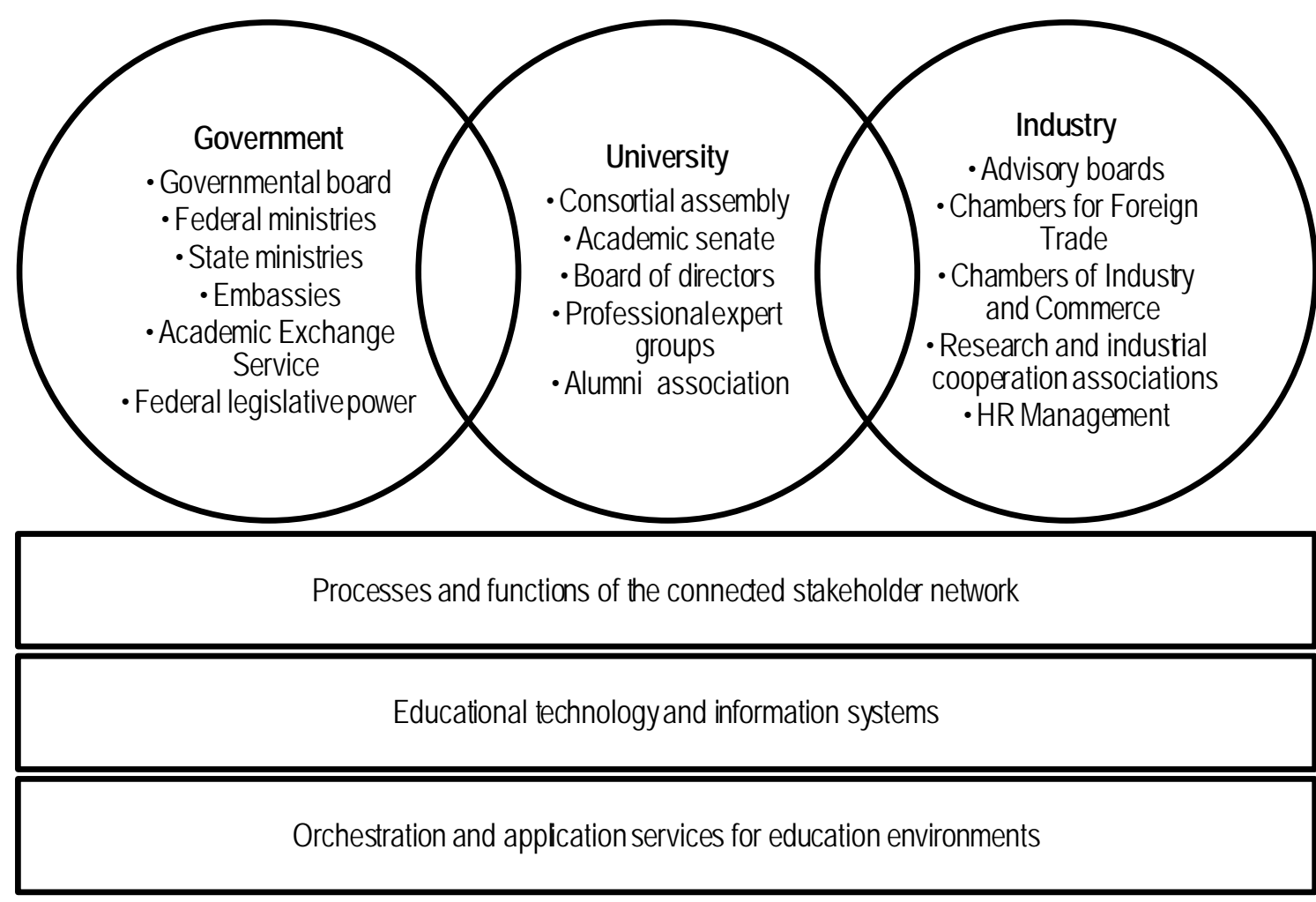

Figure 4. Educational technology connecting stakeholders in a service-based environment

The interaction of stakeholders in digitised education systems implies connecting through educational technologies according to a holistic approach, which results in a multidimensional model for the connections in different dimensions.

International double degree programs and exchange semester programs were supplemented by online components and are offered in perspective online in parity to classroom teaching with the participation and support of all stakeholders. This makes it possible for students to acquire international skills in a variety of ways, including online, and promotes virtual mobility. The prerequisite for this path was the extensive expansion of the connections with international partners.

The existing workplace impact and experience through stakeholder connectivity is complemented by online learning forms and educational technologies such as distance internship. On the other hand, new educational offers in the field of digital transformation and industry 4.0 act as catalysts for the dissemination of new technologies with a corresponding influence on the increased use of new educational technologies and their connecting effect.

Existing and developing study programmes will be further profiled in terms of education policy and society in line with the Ecosystem approach. Existing models, which include nonprofit learning, social partnerships, interdisciplinary and intercultural projects, are further qualified by educational technologies. A better connectivity of the individual forms in the 
sense of a digital ecosystem in unity of social, ecological and economic aspects will be established.

New educational technologies are used, among other things, to further improve connectivity among learners and with stakeholders. Social media plays a central role. Digital learning worlds based on further developing educational technologies influence the further development of study concepts with regard to work-life-balance, target group and application orientation, professional qualification as well as the compatibility of family, study and career. Integrated study programmes with different forms of study are better suited to the use of modern educational technologies and to implementation of lifelong learning systems.

\section{Summary}

In the course of further digitization and automation based on new educational technologies, new possibilities of better connections for the purpose of improving effectiveness in learning and educational environments arise. However, the human-centred approach has a higher priority because it is always about human potential. Therefore, the technology driven view must be linked to the behavioural view of stakeholders in educational environments through appropriate services. Such very complex educational systems and learning environments have been successively built up in iterative stages for several years. The consistent further connecting of stakeholders from different interest groups in the education sector is the prerequisite for using the advantages of new educational technologies to make teaching and learning processes more effective. Ultimately, it is a strategic decision that will only lead to success in tactically and operational terms as a holistic solution.

\section{References}

Anderman, E. M., \& Patrick, H. (2012). Achievement goal theory, conceptualization of ability/intelligence, and classroom climate. In S. L. Christenson, L. Reschly, \& C. Wylie (Eds.), The handbook of research on students engagement (pp. 173-191). Springer Science.

Banerjee, P. M., \& Belson, G. (2015). Digital education 2.0: From content to connections. Deloitte Review, 16.

European Commission (2018). Digital Education Action Plan. Communication from the Commission to the European Parliament, the Council, the European Economic and Social Committee and the Committee of the Regions. COM/2018/022 final. Brussels.

Feess, E. (2019) System. Gabler Wirtschaftslexikon, Wiesbaden. Retrieved January 27, 2019, from https://wirtschaftslexikon.gabler.de/definition/system-50117/version-273342

Freeman, R. E. (2010). Stakeholder Theory. The State of the Art. Cambridge University Press.

Hanschke, I., Giesinger, G., \& Goetze, D. (2013). Business Analyse. München.

Kirikkanat, B. (2014). Achievement motivation: Its structure and relation with learning environments. Journal of Psychological Counseling and Education, 1(1), 77-90. 
Leydesdorff, L. (2012). The Triple Helix of University-Industry-Government Relations. In E. Carayannis \& D. Campbell (Eds.), Encyclopedia of Creativity, Innovation, and Entrepreneurship. New York: Springer.

Schunk, D. H. (2014). Learning Theories: An Educational Perspective (6 ${ }^{\text {th }}$ ed.). Harlow.

Siemens, G. (2005). Connectivism: A Learning Theory for the Digital Age. International Journal of Instructional Technology \& Distance Learning, 2(1).

Stichweh, R. (2011). System theory. International Encyclopedia of Political Science. Bonn. Retrieved January 27, 2019, from https://www.fiw.unibonn.de/demokratieforschung/personen/stichweh/pdfs/80_stw_systems-theoryinternational-encyclopedia-of-political-science_2.pdf

Tittmann, C., \& Schumann, Chr.-A. (2010). Potentials for Externalizing and Measuring of Tacit Knowledge within Knowledge Nodes in the Context of Knowledge Networks. In D. Harorimana (Ed.), Cultural Implications of Knowledge Sharing, Management and Transfer. Identifying Competitive Advantage. Information Science Reference (pp. 84-107). Hershey New York.

UNESCO (1990). World Declaration on Education for All, Working Documents of the World Conference on Education for All. Jomtien. 5-7.

UNESCO Institute for Information Technologies in Education (2015). Qingdao Declaration. Seize digital opportunities, lead education transformation. PDF Version. 1-3. 